\title{
Reflections on exercise and sport in the University
}

Alison Williams

\section{Perspectives from recipe writers and interviewees}

Each person contributing their perspective on exercise and sport in the University, as a recipe author (see What have you done to my squash courts! and Exercise and sport for all) or an interviewee, shares the same passion. They agree that good health is everyone's right and should be in the University's DNA. Good health in study and work, and in a safe environment, is for everyone; it leads to better marks and academic performance, has clear productivity benefits and supports a healthier lifestyle and longevity. It is not just an aspiration for the few.

As well as interviewing the Director of Sport \& Exercise, Jim Aitken, for his recipe Exercise and sport for all, I interviewed Dr Andrew Murray, FASIC (Fitness Assessment and Sports Injuries Centre) Sports Physician and Researcher; Helen Ryall, Healthy University Project Coordinator; two 3rd-year women student gym members; and Zach Murphy, male graduate student member. The discussions were wideranging, and highlighted the multiple readings of reality (Charmaz, 2000) that emerge from differing stakeholder perspectives: gender, professional staff and student.

\section{Staff perspectives}

Dr Murray emphasised how exercise can contribute to seven years' extra life and prevention of chronic disorders, 
while regular sport makes people happier. "Getting active, and staying active really is the best thing you can do for your health. Each step is a step to health." DrMurray is aware of the barriers to people engaging in sport. He noted that: "We need to be more respectful of people who don't conform to stereotypes."

Helen Ryall, the coordinator of the Healthy University Project (HUP) prioritised supporting inactive people "who want to be a bit more active, a bit more often" and reach the recommended 150 minutes of physical activity a week. She noted that: "Women are more likely to have a conversation about health; the majority of people who engaged in conversations in the Freshers'Week health project were women."

She also observed that people very often need an impetus to make a life change; everything from, for example, having a heart attack, to having trouble keeping up with a friend while walking, or even seeing an unflattering photo of themselves. For students, who are at a key transition in their lives, there is usually an opportunity to intervene at an earlier point in the trajectory.

The SPA programme (Support for Physical Activity) is a confidential non-judgemental service open to all staff and students at the University who need some support to make the changes they want to make to their lifestyle through physical activity. HUP offers workplace programmes for staff as well as support and opportunities to students to become more active (http://www.ed.ac.uk/ sport-exercise/healthy-university).

\section{Student perspectives}

The female student member who said that the University gym is "definitely the best gym for students in Edinburgh" then went on to say: "I think as long as you know it well and begin to feel comfortable there it is a really good gym - just a question of getting used to it!"

This section examines what, for a young woman, "getting used to it" can mean, and what might be required for her to begin to feel comfortable, especially in some areas of the facility. For example:

It took several months before I felt OK going in [to the Vault Room] on my own.

The interlinking themes that emerged from the interviews with the three student members and with University Sport \& Exercise staff members are: the impact of the physical space, the sense of performance and being observed, perceptions and feelings of insider/outsider.

\section{Physical Space}

The article Stereotype threat explores how the women students may be hampered by their internalisation of societal stereotypes of what is and is not appropriate behaviour and activities for their own and other genders. There may also be a social price to pay for not conforming to gender stereotypes.

The two women students described how the different physical spaces in the gym were informally demarcated by gender. One of the students drew a 'snapshot' map (Figure 1) of the population by gender in each of the rooms during one visit to the gym:

Both women are very aware of how the different spaces within the Sport \& Exercise Pleasance building impact them.

The men dominate the space. For example, I'll wait [queue up] for a woman to finish on a bit of equipment but I wouldn't wait [queue up] for a man to be finished.

They talked of feeling intimidated in the rooms with more traditionally masculine activities (weights in particular): 
There's a feeling that the space is primarily for men.

It was several months before one felt comfortable enough to go into the weights room on her own:

The Olympic Room is male dominated. At first I wanted to be accompanied [by boyfriend or another woman] when I went in. You feel like you need permission to have access.

It's off-putting - the guys are all kitted out with the gear - big belts and things - and I feel, well, who are meant to be there?

Names make a difference. The Vault Room's name is SO masculine. It should really be called 'Intense Basement Situation'.

[It] is very male dominated, and I've never seen more than three women (including myself) in it at

A map of men and women in the CSE during a session at the gym.

$Q=$ Women

$\sigma^{\prime}=$ Men

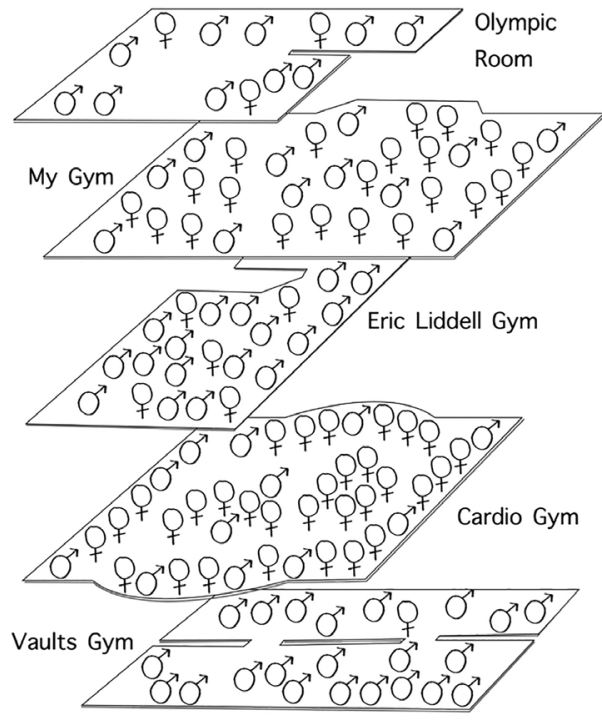

Figure 1: University Gym population, 3pm Monday 27th March 2017, charted by female student member. a time. Sometimes I'm the only woman in there to 20 guys. [...] The machines are arranged facing inwards, so that everyone is looking at each other, and there are no mirrors.

Incidentally, the Vault Room is so called because it used to be a vault in one of the old buildings in the Pleasance complex.

The Sport \& Exercise staff are aware that women may feel intimidated by the weighttraining facilities, and are now running workshops for "women who want to take up weight or strength training in a welcoming and understanding environment". The advert acknowledges that "free-weights gyms are some of the most intimidating and unwelcoming places for females due to requiring a level of competence to use and they are typically male-dominated places". Women's weightlifting workshops are selling out and encouraging more women to overcome negative perceptions surrounding strength training.

\section{Being looked at}

The issue, for young women, of feeling observed, introduces the further dynamic of performance.

The other thing is make-up - I feel I need to go to the gym in full make-up, because when I exercise I get hot and sweaty - very red in the face with a ring of white round my mouth like a mask. I wouldn't want to be seen like that."

Sometimes women go to be seen. Full make-up and just sauntering along on the treadmill very slowly...

One of the women students started sometimes going to a private central Edinburgh gym so that she can wear little or no make-up because:

I'm less likely to see anyone I know.

The feeling of being observed - the 'male gaze' (Lacan 1988; Foucault 1977; Mulvey 1975) - can be restricting 
and uncomfortable. One of the

female students said that:

The guys will make snidey

comments about underarm hair.

This theme also emerged

in the Unapologetically Me

photography exhibition.

It is not just the case in the gym, of course, as School of Education women students attending another workshop noted similar pressure at other buildings in the University:

If you go to Potterrow [a student union venue] or the main library you can see it and like hear it and if I go to the main library I feel like I should wear something nice and put on make-up. More so than if I came here [to the Education satellite campus] because it is all girls here... It's the whole male gaze thing. If you go to the main library then you feel very looked at.

The female gym members I interviewed prefer spaces where the male gaze is least in evidence, for example in the MyGym or the Cardio Gym, borne out by the snapshot map (see Figure 1).

MyGym is more female dominated. There are mirrors, and the machines face outward [away from each other] so you aren't being observed. And where there are mirrors you tend to be watching yourself to make sure you are doing things right.

The students noted that the equipment layout in MyGym and the Cardio Gym means the gender ratios in those spaces are more balanced. When designing the MyGym space, the University Sport \& Exercise staff deliberately adopted a bright and light ambience, ensured the cardio kit faced outwards, and used contemporary and attractive loose equipment. The equipment was limited to $10 \mathrm{~kg}$ to prevent 'macho' training, and there is a deliberate policy of no group or club training.
The same philosophy was adopted in the circuits and the Cardio Gym. Their aim of creating a welcoming space which was not intimidating has been successful in the sense that the gym is very popular, and $70 \%$ of those exercising there are women. It may still be the case that women prefer to exercise in proximity to other women; the students note that:

[MyGym] tends to have an informal segregation, with women congregating together in one part of the space.

\section{Fitting in}

People can also feel like outsiders in a gym for reasons unrelated to gender; there are many cues which can subtly suggest that they are not part on an "in-group". They might feel self-conscious about their bodies, or because they do not feel fit enough, or because they feel "too old". For example, a woman might feel initially uncomfortable in a class with other women if she perceives her peers to be more fit. Indeed, some staff have commented that men may be intimidated by a majority female presence at an exercise class if they are self-conscious about their body condition.

The women student members commented:

I don't see women in the gym who are any larger than a size 16, and yet it's a great way to lose weight.

I can see that divide too; there are lots of sporty men and very few 'unfit' ones! However, interestingly, I see more older men using the University Sport \& Exercise than older women although perhaps that's just the areas I frequent.

Reflecting on feelings of not fitting in, the male student member thought:

People get into a bit of a bubble when they put their headphones on. It removes one of their senses, and increases their sense of isolation in the gym [which] increases their sense of "Do I fit in?" 
The question is, how do we enhance the desirable benefits of inclusive behaviours in the gym?

Currently the Sport \& Exercise membership statistics for non-students (who make up $20 \%$ of the total membership) show that in all categories (staff, associate, community and senior) the percentage of men is much greater than of women. The staff are consequently working hard to combat people's self-perceptions that they don't belong at the gym: a key value is that the facilities are open to everyone. There are gym staff on hand (70\% female) to help orientate new members to the gym, and Sport \& Exercise aims to extend this next year with a gym buddy scheme. They offer beginner programmes in most activities to help get people started and grow confidence. Staff are trained to be warm and engaged with all members, and the centre offers around 100 exercise classes per week with $85 \%$ women attendees. The classes cover a range of exercise options and social exercise opportunities.

Sport \& Exercise has also invested heavily in improving the quality of changing provision (especially in the female areas, including saunas) to ensure the visitor has a positive experience before and after each exercise session (with attention to privacy). The cleaning staff also work to ensure a pleasant environment in the gym and changing areas to dispel myths about smelly or sweaty spaces. The staff want to ensure that people feel that they belong, and that they exercise in a pleasant environment.

In the future, it would be beneficial to conduct some further qualitative research to understand gym users' perspectives about the gym space, and gather some quantitative data on footfall in different facilities by gender, fitness level and ethnic group.

\section{Reflections}

It has been a fascinating and intriguing journey working on this article, and editing the two associated recipes (see What have you done to my squash courts! and Exercise and sport for all) which together make up this cluster about the University of Edinburgh Sport \& Exercise Pleasance Sports Complex \& Gym, evoking what Charmaz (2000) terms multiple readings of reality.

The iterative process of interviewing, writing, inviting and incorporating comments and contributions, reflection and response has brought about the "mutual creation of knowledge by the viewer and the viewed" (Charmaz, 2000, p. 510); with the addition of you, the reader, as creator of yet another reading of this reality that is the Pleasance Sports Complex.

The principal reflections arising from the recipes and interviews are, first, that Sport \& Exercises' expansion from elite sports to health and exercise has had a noticeable positive impact on student and staff membership numbers and gender balance. The interviews and recipes acknowledge and celebrate this, and the value of the changes made.

The second is that for some young women, there are challenges associated with feeling comfortable within the physical spaces of gyms, being in these spaces if they are male dominated and coping with the male gaze. The gym is not the only place where women encounter these difficulties. Women students may also feel pressure relating to body image and male gaze in student social spaces; see also the student photographs and illustrations in this volume, and for a wider sample of students refer to Stanton (2014). Students in the School of Education focus group also believed that: "There continues to be a pervasive attitude of male superiority and female objectification within some of the University's male sports clubs/teams", and commented that: "While there are policies in place, lad culture is still very prevalent in sports societies". This is borne out by evidence of sexual harassment incidents at sports societies reported in Mehdi (2013). 
These issues are also reflected more widely across the University in academic environments. In a conversation about gender equality, senior University leaders, (see Leadership perspectives on gender equality) when asked what they thought the key issues were, talked about how "there can be cultural problems". For example, one of the senior female professor's comments echo the women students' 'work-arounds' to deal with their feelings of intimidation in particular spaces:

Women coming into this [maledominated] field are more aware of the existing culture and you have to learn how to fit in. You often need to adapt. Men don't need to do this but persuading them of the value of being aware of the cultural norms and pressures can help people to see how hard it can be [if you're in the minority].

For example, during our writing workshops, a senior woman staff member told us she was intimidated by the "bear pit" atmosphere of academic meetings and a group of students explained how they found particular online learning environments hostile.
Another senior leader mentioned the "need to avoid outsider vs insider". In academic environments, stereotype threat (see Stereotype threat) can be triggered in students feeling outsiders because of their ethnicity, socio-economic status, native language or religion. In the Sport \& Exercise facilities, insider and outsider groups may emerge not only from gender but from body image perceptions and the fit compared to the unfit. Staff are aware of this and actively working to tackle these issues.

The challenge is to strike a balance of belonging and culture, to work towards an environment where, as another senior leader described it:

You want people to feel they can be themselves [...] to have their own cultures, [...] to create an environment where people can be honest, be open. 